\title{
The sixth sense in mammalian forerunners: Variability of the parietal foramen and the evolution of the pineal eye in South African Permo-Triassic eutheriodont therapsids
}

\author{
Julien Benoit, Fernando Abdala, Paul R. Manger, and Bruce S. Rubidge \\ Acta Palaeontologica Polonica 61 (4), 2016: 777-789 doi:http://dx.doi.org/10.4202/app.00219.2015
}

In some extant ectotherms, the third eye (or pineal eye) is a photosensitive organ located in the parietal foramen on the midline of the skull roof. The pineal eye sends information regarding exposure to sunlight to the pineal complex, a region of the brain devoted to the regulation of body temperature, reproductive synchrony, and biological rhythms. The parietal foramen is absent in mammals but present in most of the closest extinct relatives of mammals, the Therapsida. A broad ranging survey of the occurrence and size of the parietal foramen in different South African therapsid taxa demonstrates that through time the parietal foramen tends, in a convergent manner, to become smaller and is absent more frequently in eutherocephalians (Akidnognathiidae, Whaitsiidae, and Baurioidea) and non-mammaliaform eucynodonts. Among the latter, the Probainognathia, the lineage leading to mammaliaforms, are the only one to achieve the complete loss of the parietal foramen. These results suggest a gradual and convergent loss of the photoreceptive function of the pineal organ and degeneration of the third eye. Given the role of the pineal organ to achieve fine-tuned thermoregulation in ectotherms (i.e., "cold-blooded" vertebrates), the gradual loss of the parietal foramen through time in the Karoo stratigraphic succession may be correlated with the transition from a mesothermic metabolism to a high metabolic rate (endothermy) in mammalian ancestry. The appearance in the eye of melanopsin-containing retinal ganglion cells replacing the photoreceptive role of the pineal eye could also have accompanied its loss.

Key words: Therapsida, pineal, parietal foramen, third eye, endothermy, nocturnality, Permo-Triassic, South Africa

Julien Benoit [julien.benoit@wits.ac.za], Evolutionary Studies Institute (ESI); School of Geosciences, University of the Witwatersrand, Braamfontein 2050, Johannesburg, South Africa; School of Anatomical Sciences, University of the Witwatersrand, 7 York Road, Parktown 2193, Johannesburg, South Africa. Fernando Abdala [Nestor.Abdala@wits.ac.za], Evolutionary Studies Institute (ESI); School of Geosciences, University of the Witwatersrand, Braamfontein 2050, Johannesburg, South Africa. Paul R. Manger [Paul.Manger@wits.ac.za ], School of Anatomical Sciences, University of the Witwatersrand, 7 York Road, Parktown 2193, Johannesburg, South Africa. Bruce S. Rubidge [Bruce.Rubidge@wits.ac.za], 
Evolutionary Studies Institute (ESI); School of Geosciences, University of the Witwatersrand, Braamfontein 2050, Johannesburg, South Africa.

This is an open-access article distributed under the terms of the Creative Commons

Attribution License (for details please see creativecommons.org), which permits unrestricted use, distribution, and reproduction in any medium, provided the original author and source are credited.

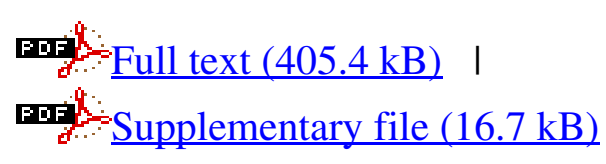

